\title{
Pharmacists as immunizers in Lebanon: a national survey of community pharmacists' willingness and readiness to administer adult immunization
}

\author{
Dalal Youssef $f^{1,2^{*}}$, Linda Abou-Abbas Li, $^{3,4}$, Suzan Farhat ${ }^{5}$ and Hamad Hassan ${ }^{6}$
}

\begin{abstract}
Background: Since the focus of healthcare has shifted toward prevention, pharmacists were highly encouraged to expand their practice to include immunization services. Our study aimed to assess the knowledge, attitudes and beliefs of community-based Lebanese pharmacists, in addition to their willingness to expand their practice scope to include vaccine administration.

Methods: A cross-sectional study was conducted during the phase preceding the arrival of the COVID-19 vaccine in Lebanon between 1 and 31st December 2020. Using a stratified random sampling method, data were collected from Lebanese community pharmacists (CPs) through an online survey that included information on socio-demographic characteristics, clinical experience, willingness to administer vaccines, knowledge about vaccination, attitudes towards immunization, reasons supporting utilizing pharmacists as immunizers and the requested elements to incorporate immunization in pharmacists' practice scope. Multivariable analyses were performed to identify the factors associated with knowledge.
\end{abstract}

Results: A total of 412 community pharmacists participated in this survey. Of the total, $66.5 \%$ of the surveyed CPs are willing to administer vaccines. The majority of them (89.8\%) had an overall good level. Out of all, $92.7 \%$ showed a positive overall attitude score toward immunization, $95.4 \%$ agreed that community pharmacists can play an important role in advertising and promoting vaccination. The main needed elements for implementing immunization services in pharmacies listed by participants were: support of health authorities (99.3\%), statutory allowance (82.8\%), patient demand (95.4\%), pharmacist's interest (96.1\%) and continuous education and training workshops on immunization. Older CPs (50 years and above) [aOR $=0.703, \mathrm{Cl} 95 \%(0.598-0.812)]$ and those working in Bekaa and North have lower knowledge score than their counterparts. High educational level [aOR $=1.891, \mathrm{Cl} 95 \%$ (1.598-2.019)], previous experience in immunization $[\mathrm{aOR}=3.123, \mathrm{Cl} 95 \%(2.652-4.161)]$ and working in urban areas $[\mathrm{aOR}=3.640, \mathrm{Cl} 95 \%$ (2.544-4.717)] were positively associated with a good knowledge level.

Conclusion: Most of Lebanese community pharmacists are willing to offer immunizations. The expansion of the pharmacists practice scope to include provision of immunizations required a national plan that encompasses

*Correspondence: dalalyoussef.esu@gmail.com; dyoussef@moph.gov.lb

1 Preventive Medicine Department, Ministry of Public Health, Beirut, Lebanon

Full list of author information is available at the end of the article permits use, sharing, adaptation, distribution and reproduction in any medium or format, as long as you give appropriate credit to the original author(s) and the source, provide a link to the Creative Commons licence, and indicate if changes were made. The images or other third party material in this article are included in the article's Creative Commons licence, unless indicated otherwise in a credit line to the material. If material is not included in the article's Creative Commons licence and your intended use is not permitted by statutory regulation or exceeds the permitted use, you will need to obtain permission directly from the copyright holder. To view a copy of this licence, visit http://creativecommons.org/licenses/by/4.0/. The Creative Commons Public Domain Dedication waiver (http://creativeco mmons.org/publicdomain/zero/1.0/) applies to the data made available in this article, unless otherwise stated in a credit line to the data. 
strengthening knowledge, training, certification for eligibility to administer vaccines, enhancing pharmacovigilance and statutory reform.

Keywords: Community pharmacists, Immunization, Willingness, Readiness, Lebanon

\section{Introduction}

Immunization is considered as one of the most costeffective strategy for disease prevention [1]. Despite its known benefits, adult immunization rates worldwide fall below desired targets [2]. Many factors have been identified as barriers towards achievement of target immunization coverage rates, including general public apathy, concerns and misconceptions about the safety and efficacy of vaccines, cost, lack of access to immunizers and convenience [3]. Thus, in order to improve immunization rate, there is an urgent need to address these barriers.

Since the focus of healthcare has shifted toward prevention, pharmacists were highly encouraged to expand their practice to incorporate preventive measures including immunization $[4,5]$. Besides, one of the suggested strategies to succeed in an immunization program and increase the coverage rates among adults lies in involving pharmacists in vaccine administration [6]. This extension in the practice scope can be achieved through different ways such as starting by advocating immunization through raising awareness about the benefits of vaccine among the public, particularly pharmacy visitors, discussing the patient's immunization status and recommending vaccines during the patient's visit to the pharmacy. Lastly, pharmacists, especially community ones, can be potential immunizers by administering vaccines in their practice setting [7].

In their attempt to increase the rate of immunization, many countries have adopted the strategy of involving non-traditional immunization providers and, thus, allowing pharmacists to administer vaccines [8]. Many studies intended to highlight the positive effects of implementing vaccinations in community pharmacies. The results of these studies showed that pharmacists increase the availability of vaccinations, accelerate immunization, effectively educate patients, affect the vaccination coverage rate, prevent new cases of diseases, and by reducing the number of diseases or complications, they bring savings to the healthcare system [9-13]. Experiences in countries, who adopted the mentioned strategy such as England, Portugal, and the United States, prove the benefits of pharmacy-driven vaccination for both patients and the healthcare system [14]. Similarly, in Canada, following the implementation of vaccination administered by pharmacists, the proportion of people vaccinated in the general population has increased significantly [15].
In Lebanon, the distribution of community pharmacies among Lebanese province is not equitable and its ownership is private on a for-profit basis [16]. According to the Lebanese Order of Pharmacists (OPL) and the Ministry of Public Health (MOPH) laws, pharmacists should be omnipresent during the pharmacy's opening hours. However, they are not permitted by law to administer vaccines. Their role is only restricted to dispense vaccines received from pharmaceutical companies. This year has witnessed a debate about allowing pharmacists to administer influenza vaccine as applied in other countries. Subsequently, MOPH has issued a memorandum No. 149 in October 6th 2020 to assert the restricted role of CPs with regard to vaccine administration. However, based on some observations, it is commonly found that many pharmacists CPs influenza vaccines to their patients as part of their current practices. In addition, it is well known that Lebanese pharmacists are actively involved in raising awareness and public health promotion [17]. In the light of COVID-19 pandemic and the need to enroll a national vaccination plan and prior to embarking on a program expanding the scope of pharmacy practice to include the provision of immunizations, it is important to understand the intention of the Lebanese pharmacist to become an immunization provider. Such information highlights the importance of policy change and legal reform toward expanding the scope of pharmacy practice. Thus, our study aims to assess the knowledge, attitudes and beliefs of community-based Lebanese pharmacists with respect to expanding their scope of practice, in addition to their willingness to participate in vaccine administration.

\section{Methods}

\section{Study design and population}

A cross-sectional study using an internet-based survey was conducted during the phase preceding the arrival of the COVID-19 vaccine in Lebanon between 1 and 31st December 2020. Pharmacists were electronically invited to participate. A stratified random sampling method was used in this survey to select a representative sample of CPs from the eight Lebanese provinces. The number of CPs selected from each province was calculated using a probability-proportion to size sampling method based on the list of CPs provided by the OPL. CPs working currently in pharmacy setting and who agreed to participate to the study were eligible for participation. Exclusion 
criteria included: clinical pharmacists, retired CPs, those who were out of the country at the time of the survey, as well as those not practicing actually. Pharmacists who were unreachable due to change of their contact information during the time of the survey and those who refused to participate in the study were also excluded.

\section{Questionnaire development}

A 58-item questionnaire was developed and designed specifically by the authors to assess the study objectives and to cover important aspects of pharmacists as immunizers. It was drafted, piloted and modified prior to distribution. A panel of experts involving both rural and urban pharmacists provided comments on the survey design. They were asked to provide qualitative feedback on clarity, wording, interpretability and relevance. Then, the original English draft of the questionnaire was translated and adapted to the Arabic language based on standard translation guidelines [18]. The questionnaire was pre-tested among 30 community pharmacists for survey flow, functionality, readability, comprehension of instructions, and clarity. Based upon feedback from the pre-test, minor modifications regarding readability and clarity were made to the questionnaire. Furthermore, the reliability of the questionnaire was checked. The average time for filling the survey was $12 \mathrm{~min}$. The questionnaire was self-administered and consisted of close-ended questions. It was divided into 6 domains:

1. Baseline information of participants: including age, gender, profile, educational level, clinical experience and working hours in addition to information about the pharmacy (location, opening hours...).

2. Pharmacists' willingness to administer adult vaccines.

3. Pharmacists' knowledge about vaccination.

4. Pharmacists' specific immunization attitudes.

5. Reasons supporting utilizing pharmacists as immunizers.

6. Elements needed to incorporate immunization in pharmacists' practice scope.

Knowledge and attitude scores were computed. Participants' overall knowledge and overall attitude were categorized using modified Bloom's cut-off point as good if the score was equal or more than $60 \%$, and poor if the score was less than $60 \%$.

\section{Sample size calculation}

To calculate the sample size of the study, the Raosoft sample size calculator was used. Based on a total population size of 4185 community pharmacies registered with OPL, a 95\% confidence level and an absolute error of
$5 \%$, a minimal sample of 352 pharmacists was required to allow adequate power for bivariate and multivariable analyses.

\section{Data collection}

An anonymous online questionnaire using a Google form was sent using WhatsApp or email to all community pharmacists. Then, pharmacists were contacted via phone call and notified about the survey and its purpose. The link of the study included a brief introduction to the background, the objective of the survey, and instructions for filling the questionnaire.

\section{Ethical considerations}

A written informed consent was obtained for each participant. They were reassured that their participation is voluntary and that they are free to withdraw at any time. In addition, all information was gathered anonymously and handled confidentially. The study design assured adequate protection of study participants, and neither included clinical data about patients nor configured itself as a clinical trial. Hence, this study was exempted from ethical approval of the ministry of Public Health.

\section{Statistical analysis}

The collected data were checked for completeness and consistency before analysis. The data were analyzed using the statistical software SPSS (Statistical Package for Social Sciences), version 22.0. A reliability analysis was done to validate each of these scores and was performed using the Cronbach's alpha test. A coefficient of above 0.7 indicated a good internal consistency. Descriptive statistics were reported using frequency and percentages for categorical variables. Finally, the analyzed data were organized and presented in the tabular, graphical and narrative form as necessary.

\section{Results}

\section{Baseline characteristics of the study participants}

Table 1 shows the baseline characteristics of the participants. A total of 412 community pharmacists participated in this survey of which $54.9 \%$ are females. Most of them $(62.4 \%)$ are aged less than 40 years. More than half of them $(55.1 \%)$ are pharmacy owners and $55.6 \%$ have a bachelor of science (BS) in pharmaceutical sciences. With respect to their work, $43.7 \%$ of them have a work experience of more than 10 years as community pharmacist and only $23.3 \%$ have no previous experience in immunization. Regarding pharmacy distribution, the majority of pharmacists (68\%) work in urban area particularly in Mount-Lebanon province (37.6\%). Lastly, the majority of pharmacies where our participants work (55.30\%) are opened $80-120 \mathrm{~h}$ per week. 
Table 1 Baseline characteristics of the participants $(N=412)$

\begin{tabular}{|c|c|c|}
\hline & $n$ & $\%$ \\
\hline \multicolumn{3}{|l|}{ Gender } \\
\hline Male & 186 & $45.10 \%$ \\
\hline Female & 226 & $54.90 \%$ \\
\hline \multicolumn{3}{|l|}{ Age (years) } \\
\hline $20-29$ & 128 & $31.10 \%$ \\
\hline $30-39$ & 129 & $31.30 \%$ \\
\hline $40-49$ & 81 & $19.70 \%$ \\
\hline Equal or more than 50 & 74 & $18.00 \%$ \\
\hline \multicolumn{3}{|l|}{ Profile } \\
\hline Manager & 44 & $10.70 \%$ \\
\hline Owner & 227 & $55.10 \%$ \\
\hline Staff pharmacist & 141 & $34.20 \%$ \\
\hline \multicolumn{3}{|l|}{ Educational level } \\
\hline BS in pharmaceutical sciences & 229 & $55.60 \%$ \\
\hline Pharm D & 102 & $24.80 \%$ \\
\hline Master, PhD or more & 81 & $19.70 \%$ \\
\hline \multicolumn{3}{|l|}{ Years of experience } \\
\hline Less than 5 years & 137 & $33.30 \%$ \\
\hline $5-10$ years & 95 & $23 \%$ \\
\hline More than 10 years & 180 & $43.70 \%$ \\
\hline \multicolumn{3}{|l|}{ Previous experience in immunization } \\
\hline No & 96 & $23.30 \%$ \\
\hline Yes & 316 & $76.70 \%$ \\
\hline \multicolumn{3}{|l|}{ Pharmacist's working hours per week } \\
\hline $24 \mathrm{~h}$ or less & 93 & $23.60 \%$ \\
\hline $25-40 h$ & 87 & $21.10 \%$ \\
\hline More than $40 \mathrm{~h}$ & 232 & $56.30 \%$ \\
\hline \multicolumn{3}{|l|}{ Geographic location of the pharmacy } \\
\hline Rural & 132 & $32 \%$ \\
\hline Urban & 280 & $68 \%$ \\
\hline \multicolumn{3}{|l|}{ Province } \\
\hline Mount-Lebanon & 155 & $37.6 \%$ \\
\hline Beirut & 73 & $17.72 \%$ \\
\hline Nabatyeh + South & 94 & $22.8 \%$ \\
\hline Great Bekaa (Bekaa + Baalbeck-Hermel) & 42 & $10.2 \%$ \\
\hline Great North(North + Akkar) & 48 & $11.65 \%$ \\
\hline \multicolumn{3}{|l|}{ Number of hours/week pharmacy is open } \\
\hline Less than $80 \mathrm{~h}$ & 153 & $37.20 \%$ \\
\hline $80-120 \mathrm{~h}$ & 228 & $55.30 \%$ \\
\hline 7 days $24 / 24$ & 31 & $7.50 \%$ \\
\hline
\end{tabular}

$N$ frequency, $\%$ percentage, $95 \% \mathrm{Cl} 95 \%$ confidence interval

\section{Willingness to be an immunizer}

Of the total, $66.5 \%$ of the surveyed community pharmacists are willing to administer vaccines at this time, if they were legally permitted by the legislation to administer vaccines to adults without additional trainings. The willingness to incorporate this service into their practice rises to $94.4 \%$ if the legislation was combined to an immunization program or certification program (Figs. 1, 2).

\section{Pharmacists self-reported knowledge}

The majority of surveyed pharmacists $(89.8 \%)$ had an overall good level of knowledge $(\geq 60 \%)$ and only $10.2 \%$ of them had a poor level of knowledge $(<60 \%)$. Table 2 illustrates the knowledge domains about vaccination. The majority of respondents were knowledgeable in different domains except the domain related to vaccine contraindications and precautions. The highest knowledge scales were shown in the general knowledge about vaccination (99.3\%) and the domain specific to influenza vaccination (90.5\%). Besides, around three-quarters of respondents were well informed about the storage, administration and adverse reactions of vaccines.

Table 3 describes pharmacists' answers to vaccination knowledge items. Despite the good level of knowledge recorded in the domain related to the storage and administration of vaccines, only $45.4 \%$ of pharmacists were aware that inactivated vaccines may be administered at

Willingness to incorporate vaccination service into your practice/business without additional training if it is legally permitted?

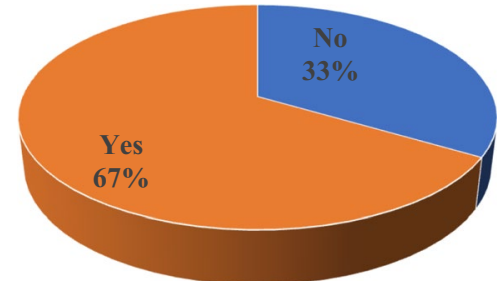

Fig. 1 At this time, if you were legally permitted by the legislation to administer vaccines to adults, are you willing to incorporate this service into your practice/business without additional training?

Willingness to incorporate vaccination service into practice after attending an immunization training or certification program and being legally permitted

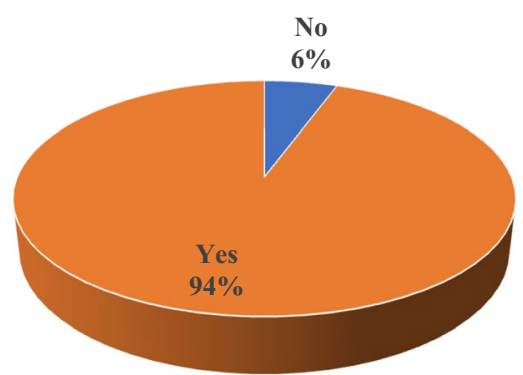

Fig. 2 If an immunization training or certification program was available to you, and you were legally permitted by the legislation to administer vaccines to adults, are you willing to incorporate this service into your practice/business? 
Table 2 Pharmacist's knowledge domains

\begin{tabular}{llrr}
\hline & & Poor & Good \\
& & $\boldsymbol{n}(\%)$ & \\
\hline D1 & Domain 1: General knowledge & $3(0.7 \%)$ & $409(99.3 \%)$ \\
D2 & Domain 2: Influenza vaccines & $39(9.5 \%)$ & $373(90.5 \%)$ \\
D3 & Domain 3: Contraindications and precautions to vaccination & $284(68.9 \%)$ & $128(31.1 \%)$ \\
D4 & Domain 4: Storage and administration of vaccine & $114(27.7 \%)$ & $298(72.3 \%)$ \\
D5 & Domain 5: Adverse reactions following vaccination & $102(24.8 \%)$ & $310(75.2 \%)$ \\
& Overall knowledge & $42(10.2 \%)$ & $370(89.8 \%)$ \\
\hline
\end{tabular}

the same time or at any time before or after a live vaccine. Similarly, $45.4 \%$ of them were not knowledgeable about the fact that local adverse reaction such as pain, swelling, and redness at the injection site generally occurred within few hours of the injection, and are usually mild and self-limited.

In respect of the contraindications and precautions domains of vaccine, only $26 \%$ of participants considered that pneumococcal vaccination is not contraindicated for asplenic patients.

\section{Pharmacists' specific immunization attitudes}

Out of all, 92.7\% of surveyed pharmacists showed a positive overall attitude score toward immunization. Around $90 \%$ of them considered that vaccines produce more health benefits than health risks, and that increasing the proportion of adults who receive recommended immunizations is important. However, only $20.4 \%$ of them considered that natural infection or a healthy lifestyle are effective alternatives to vaccines.

\section{Reasons supporting utilizing pharmacists as immunizers}

The majority of respondents (95.4\%) agreed that community pharmacists can play an important role in advertising and promoting vaccination. Moreover, more than $90 \%$ of them considered that allowing pharmacists to vaccinate can reduce costs paid by patients, and that pharmacies are easily accessible to the community which will improve the overall vaccination rate among adults as they feel more comfortable. In addition, $84.7 \%$ of them agreed that pharmacists should be legally permitted to administer vaccines. However, only $50 \%$ of respondents agreed that pharmacists have received adequate teaching/training about vaccine administration during their education (Fig. 3).

\section{Elements needed for implementing immunization services in pharmacies}

The main needed elements for implementing immunization services in pharmacies listed by participants were: support of health authorities (Ministry of Public Health and Order of Lebanese Pharmacists) (99.3\%), statutory allowance (82.8\%), patient demand (95.4\%), pharmacist's interest (96.1\%) and continuous education and training workshops on immunization, safe administration and handling of vaccines (93.7\%). Only $55.6 \%$ of participated pharmacists highlighted the need of formal certification in vaccine administration as requisite for allowing pharmacists to be immunizers (Table 4).

\section{Factors associated with good knowledge among CPs}

Table 5 displays the factors associated with good knowledge score among CPs. Older CPs aged 50 years and above $[\mathrm{aOR}=0.703$, 95\% CI $(0.598-0.812)]$ were less knowledgeable than younger CPs aged between 20 and 39 years old. CPs with higher education level than BS in pharmaceutical sciences $[\mathrm{aOR}=1.891$, CI $95 \%$ (1.598-2.019)] and previous experience in immunization $[\mathrm{aOR}=3.123$, CI 95\% (2.652-4.161)] were more likely to have a good knowledge score than those who have a BS degree in pharmaceutical sciences and who lack from previous experience in immunization. CPs working in pharmacies located in urban areas $[\mathrm{aOR}=3.640$, CI 95\% (2.544-4.717)] showed better level of knowledge than their counterparts working in rural areas. Our findings showed also that CPs working in Great Bekaa $[\mathrm{aOR}=0.703$, CI 95\% (0.598-0.812) $]$ and great North have lower odds of good knowledge than those working in Beirut.

\section{Discussion}

This study was conducted during the preparedness phase for the roll-out of COVID-19 vaccines in Lebanon. It has particular importance during the COVID-19 pandemic as pharmacists could have a responsibility to take a prominent role in combating infectious diseases and control programs in health-care systems, in addition to their significant impact on the vaccination coverage rate. To the best of our knowledge, this is the first representative national Lebanese study aiming to explore readiness and 
Table 3 Pharmacists' answers to knowledge items

\begin{tabular}{|c|c|c|c|c|}
\hline \multicolumn{2}{|l|}{$\#$} & $\begin{array}{l}\text { Correct } \\
n(\%)\end{array}$ & $\begin{array}{l}\text { Incorrect } \\
n(\%)\end{array}$ & $\begin{array}{l}\text { I don't Know } \\
n(\%)\end{array}$ \\
\hline \multicolumn{5}{|c|}{ D1: General knowledge } \\
\hline K1 & Vaccines are critical to the prevention and control of infectious diseases outbreaks & 409 (99.3\%) & $3(0.7 \%)$ & $0(0 \%)$ \\
\hline K2 & The ingredients of the vaccine include: the antigen, adjuvants, preservatives, and stabilizers & $375(91 \%)$ & $6(1.5 \%)$ & $31(7.5 \%)$ \\
\hline K3 & Vaccines are safe and serious problems from the vaccine are very rare & $383(93 \%)$ & $20(7 \%)$ & $9(2.2 \%)$ \\
\hline K4 & Every vaccine must go through extensive and rigorous testing before it can be introduced & $402(97.6 \%)$ & $6(1.4 \%)$ & $4(1 \%)$ \\
\hline K5 & During the COVID-19 pandemic, vaccination continues to be critically important & $396(96.1 \%)$ & $6(1.4 \%)$ & $10(2.5 \%)$ \\
\hline K6 & $\begin{array}{l}\text { Vaccines reduce the risks of getting a disease by working with the body's natural defenses to build } \\
\text { protection }\end{array}$ & $412(100 \%)$ & $0(0 \%)$ & $0(0 \%)$ \\
\hline K7 & $\begin{array}{l}\text { Not all vaccinations may be needed in Lebanon, some may only be given prior to travel, or to } \\
\text { people in high-risk }\end{array}$ & $334(81.1 \%)$ & $78(18.9 \%)$ & $4(1 \%)$ \\
\hline K8 & $\begin{array}{l}\text { Following the introduction of a vaccine, close monitoring continues to detect any unexpected } \\
\text { adverse side effects and assess the effectiveness }\end{array}$ & $377(91.5 \%)$ & $22(5.3 \%)$ & $13(3.2 \%)$ \\
\hline K9 & $\begin{array}{l}\text { Vaccines protect us throughout life and at different ages, from birth to childhood, as teenagers, and } \\
\text { into old age }\end{array}$ & $378(91.7 \%)$ & $28(6.8 \%)$ & $6(1.5 \%)$ \\
\hline \multicolumn{5}{|c|}{ D2: Influenza vaccination } \\
\hline K10 & Unvaccinated people with mild symptoms of influenza can spread the disease to others & $383(93 \%)$ & $22(5.3 \%)$ & $7(1.7 \%)$ \\
\hline K11 & The seasonal flu vaccine protects against the most common influenza viruses including H1N1 & $358(86.9 \%)$ & $38(9.2 \%)$ & $16(3.9 \%)$ \\
\hline K12 & $\begin{array}{l}\text { Annual influenza immunization is recommended for all health-care professionals in contact with } \\
\text { individuals in high-risk groups }\end{array}$ & $404(98.1 \%)$ & $8(1.9 \%)$ & $0(0 \%)$ \\
\hline K13 & Anyone can get very sick from influenza, including people who are healthy & $334(81.1 \%)$ & $66(16 \%)$ & $12(2.9 \%)$ \\
\hline \multicolumn{5}{|c|}{ D3: Contraindications and precautions to vaccination } \\
\hline K14 & Pneumococcal vaccination is contraindicated for asplenic (without a spleen) patients & $107(26 \%)$ & $103(25 \%)$ & $202(49 \%)$ \\
\hline K15 & Breastfeeding is a contraindication to vaccination & $292(70.9 \%)$ & $47(11.3 \%)$ & $73(17.8 \%)$ \\
\hline K16 & $\begin{array}{l}\text { Pregnant women who are expected to deliver during the influenza season should not receive the } \\
\text { influenza vaccine }\end{array}$ & $300(72.8 \%)$ & $56(13.6 \%)$ & $56(13.6 \%)$ \\
\hline K17 & $\begin{array}{l}\text { Anaphylactic reaction to a previous dose of vaccine or a vaccine component is a contraindication to } \\
\text { further doses of the same vaccine or to the same component in other vaccines }\end{array}$ & $387(93.9 \%)$ & $7(1.5 \%)$ & $18(4.4 \%)$ \\
\hline K18 & Persons receiving immunosuppressive medications should not receive the influenza vaccine & $204(49.5 \%)$ & $134(32.5 \%)$ & $74(18 \%)$ \\
\hline K19 & $\begin{array}{l}\text { Live-virus vaccines (MMRII...) should be postponed until after chemotherapy or high-dose steroid } \\
\text { has ended }\end{array}$ & $342(83 \%)$ & $25(6.3 \%)$ & $45(10.7 \%)$ \\
\hline \multicolumn{5}{|c|}{ D4: Storage and administration of vaccine } \\
\hline K20 & Improper storage of vaccines may affect the immune response of the vaccine recipient & $384(93.2 \%)$ & $7(1.7 \%)$ & $21(5.1 \%)$ \\
\hline K21 & Stabilizers protect the vaccine during storage and transportation & $356(86.4 \%)$ & $26(6.3 \%)$ & $30(7.3 \%)$ \\
\hline K22 & $\begin{array}{l}\text { Inactivated vaccines may be administrated at the same time or at any time before or after a live } \\
\text { vaccine }\end{array}$ & $187(45.4 \%)$ & $112(27.2 \%)$ & $113(27.4 \%)$ \\
\hline K23 & A person who received a live vaccine should wait 28 days before receiving another live vaccine & $291(70.6 \%)$ & $48(11.7 \%)$ & $73(17.7 \%)$ \\
\hline \multicolumn{5}{|c|}{ D5: Adverse reactions following vaccination } \\
\hline K24 & $\begin{array}{l}\text { Local adverse reaction such as pain, swelling, and redness at the injection site generally occurred } \\
\text { within a few hours of the injection and are usually mild and self-limited }\end{array}$ & $187(45.4 \%)$ & $219(53.1 \%)$ & $6(1.5 \%)$ \\
\hline K25 & $\begin{array}{l}\text { Systemic adverse reactions may occur following receipt of live, attenuated vaccines which must } \\
\text { replicate to produce immunity }\end{array}$ & $283(68.7 \%)$ & $85(20.6 \%)$ & $44(10.7 \%)$ \\
\hline K26 & $\begin{array}{l}\text { A systemic reaction is usually mild and occurs 3-21 days after the vaccine was administrated (incu- } \\
\text { bation period of the vaccine) }\end{array}$ & $318(77.2 \%)$ & $23(5.5 \%)$ & $71(17.2 \%)$ \\
\hline K27 & Severe allergic reactions may be life-threatening but fortunately, they are rare & $386(93.7 \%)$ & $10(2.4 \%)$ & $16(3.9 \%)$ \\
\hline K28 & The risk of an allergic reaction can be decreased by effective screening prior to vaccination & $316(76.7 \%)$ & $43(10.5 \%)$ & $53(12.8 \%)$ \\
\hline K29 & $\begin{array}{l}\text { Providers should report any clinically significant adverse event occurring after administration of the } \\
\text { vaccine even if they are unsure whether the vaccine caused the event }\end{array}$ & $400(97.1 \%)$ & $3(0.7 \%)$ & $9(2.2 \%)$ \\
\hline
\end{tabular}


Community pharmacists can play an important role in advertising and promoting vaccination

Allowing pharmacists to vaccinate can reduce costs of vaccination paid by patients

Community pharmacists are easily accessible to the community (hours of availability, geographical distribution....)

Providing vaccination through community pharmacy will improve the overall rate of vaccination among adults

Pharmacists should be permitted to expand their practice to include the administration of recommended adult vaccines.

If pharmacists were permitted to immunize, most adults would feel comfortable receiving their recommended vaccinations from a pharmacist.

Pharmacists have good knowledge of vaccines and their indications and contraindications

Community pharmacists received adequate teaching/training about vaccine administration during their pharmacy training.

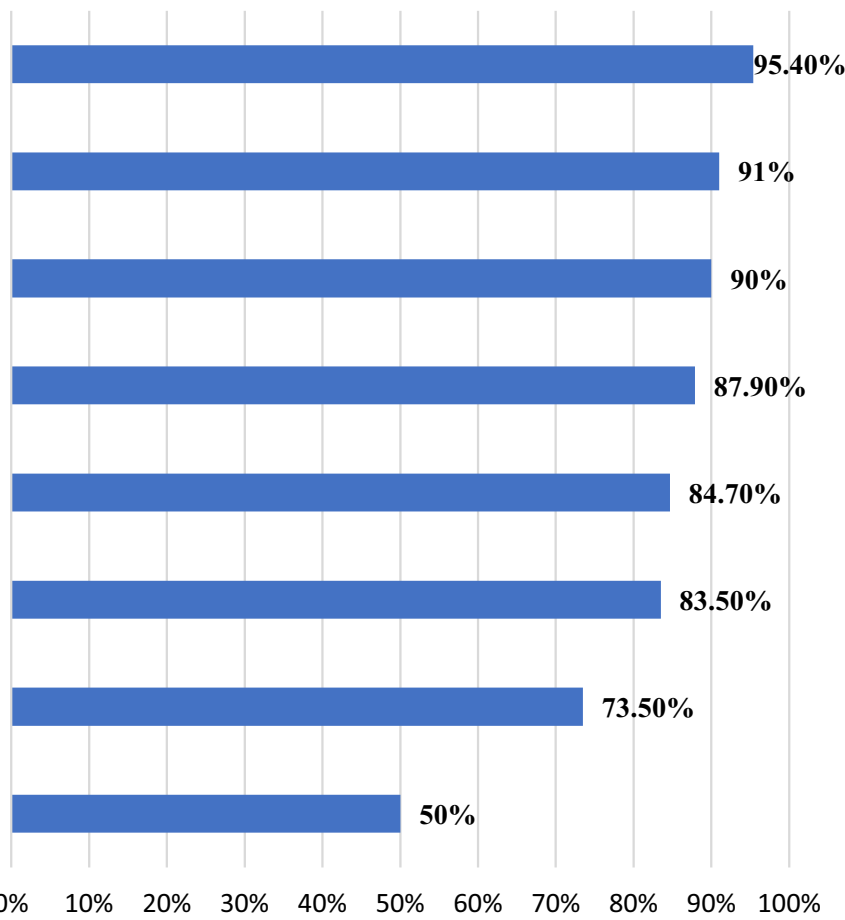

- \% of agreement

Fig. 3 Reasons supporting utilizing pharmacists as immunizers as perceived by CPS

Table 4 Elements needed for implementing immunization services in pharmacies

\begin{tabular}{|c|c|c|c|}
\hline & & $\begin{array}{l}\text { No } \\
n(\%)\end{array}$ & $\begin{array}{l}\text { Yes } \\
n(\%)\end{array}$ \\
\hline E1 & More university education and training on immunization administration for pharmacists are needed & $67(16.3 \%)$ & $345(83.7 \%)$ \\
\hline E2 & Formal certification in vaccine administration should be required for pharmacists & $183(44.4 \%)$ & $229(55.6 \%)$ \\
\hline E3 & Continuous education and training workshops on immunization, safely administration and handling of vaccines & $26(6.3 \%)$ & $386(93.7 \%)$ \\
\hline E4 & Financial reimbursement or adequate remuneration & $66(16 \%)$ & $346(84 \%)$ \\
\hline E5 & Patients demand & $19(4.6 \%)$ & $393(95.4 \%)$ \\
\hline E6 & Collaboration with medical clinics & $86(20.9 \%)$ & $326(79.1 \%)$ \\
\hline E7 & Support from medical and nursing associations & $76(18.4 \%)$ & $336(81.6 \%)$ \\
\hline E8 & Support of health authorities (Ministry of Public Health and Order of Lebanese Pharmacists) & $3(0.7 \%)$ & $409(99.3 \%)$ \\
\hline E9 & Pharmacist interest & $16(3.9 \%)$ & $396(96.1 \%)$ \\
\hline E10 & Legal issue & $71(17.2 \%)$ & $341(82.8 \%)$ \\
\hline
\end{tabular}

willingness of community pharmacists to expand their practice scope into administering vaccines for adults.

The main findings in our study were that more than half of the surveyed community pharmacists are willing to start in the meantime the administration of vaccines in case they were legally permitted to do it without additional training. However, this willingness to incorporate this service into their practice rises to more than $90 \%$ if the legislation was combined to an education or certification program. This could be explained by the fact that despite their willingness to proceed, many pharmacists felt not well prepared, given that their education was not sufficient to begin at this time incorporating immunization services at their practice, and that formal certification should be required to do so. In this context, many pharmacist regulatory bodies have recognized the stipulation of proper immunization training prior to service provision, hence, the need of 
Table 5 Multivariable logistic regression of the factors associated with knowledge of CPS

\begin{tabular}{|c|c|c|c|c|c|c|}
\hline & \multicolumn{2}{|c|}{ Overall knowledge } & \multirow[t]{3}{*}{$P$-value } & \multirow[t]{3}{*}{$\mathrm{aOR}$} & \multicolumn{2}{|l|}{$\mathrm{Cl} 95 \%$} \\
\hline & \multirow{2}{*}{$\begin{array}{l}\text { Poor } \\
n(\%)\end{array}$} & \multirow{2}{*}{$\begin{array}{l}\text { Good } \\
n(\%)\end{array}$} & & & \multirow[b]{2}{*}{ Lower } & \multirow[b]{2}{*}{ Uppe } \\
\hline & & & & & & \\
\hline Gender & & & 0.089 & & & \\
\hline Male & $16(38.1 \%)$ & 170 (61.9\%) & & & & \\
\hline Female & $26(11.5 \%)$ & $200(88.5 \%)$ & & & & \\
\hline Age (years) & & & 0.023 & & & \\
\hline $20-39$ & $15(5.8 \%)$ & $242(94.2 \%)$ & Ref & & & \\
\hline $40-49$ & $6(7.5 \%)$ & $75(92.5 \%)$ & 0.143 & 0.813 & 0.765 & 1.354 \\
\hline $50-59$ & $9(16.9 \%)$ & $44(83.1 \%)$ & 0.038 & 0.703 & 0.598 & 0.812 \\
\hline Equal or more than 60 & $12(57.1 \%)$ & $9(42.9 \%)$ & 0.021 & 0.604 & 0.478 & 0.756 \\
\hline Profile & & & 0.207 & & & \\
\hline Manager & $10(22.7 \%)$ & $34(77.3 \%)$ & & & & \\
\hline Staff pharmacist & $20(14.2 \%)$ & $121(85.8 \%)$ & & & & \\
\hline Owner & $12(5.6 \%)$ & $215(94.4 \%)$ & & & & \\
\hline Educational level & & & 0.012 & & & \\
\hline BS in pharmaceutical sciences & $29(12.7 \%)$ & $200(87.3 \%)$ & Ref & & & \\
\hline More than BS & $13(7.1 \%)$ & $170(92.9 \%)$ & 0.039 & 1.891 & 1.598 & 2.019 \\
\hline Years of experience & & & 0.106 & & & \\
\hline$<5$ years & $20(14.6 \%)$ & $117(85.4 \%)$ & & & & \\
\hline $5-10$ years & 13(13.7\%) & $82(86.3 \%)$ & & & & \\
\hline More than 10 years & $9(5 \%)$ & $171(95 \%)$ & & & & \\
\hline Previous experience in immunization & & & 0.008 & & & \\
\hline No & $29(30.2 \%)$ & $67(69.8 \%)$ & Ref & & & \\
\hline Yes & $13(4.1 \%)$ & $303(95.9 \%)$ & $<0.001$ & 3.123 & 2.652 & 4.161 \\
\hline Geographic location of the pharmacy & & & $<0.001$ & & & \\
\hline Rural & $32(24.2 \%)$ & $100(75.6 \%)$ & Ref & & & \\
\hline Urban & $10(3.6 \%)$ & $270(96.4 \%)$ & $<0.001$ & 3.64 & 2.544 & 4.717 \\
\hline Province (pharmacy) & & & 0.045 & & & \\
\hline Mount-Lebanon & $7(4.5 \%)$ & $148(95.5 \%)$ & Ref & & & \\
\hline Beirut & $4(5.5 \%)$ & $69(94.5 \%)$ & 0.165 & 0.815 & 0.712 & 1.103 \\
\hline Nabatyeh + South & $6(6.4 \%)$ & $88(93.6 \%)$ & 0.112 & 0.693 & 0.567 & 1.012 \\
\hline Great Bekaa(Baalbeck-Hermel + Bekaa) & $11(26.2 \%)$ & $31(73.8 \%)$ & 0.041 & 0.185 & 0.112 & 0.223 \\
\hline Great North(Akkar + North) & $14(29.2 \%)$ & $34(70.8 \%)$ & 0.029 & 0.198 & 0.143 & 0.318 \\
\hline Number of hours/week pharmacy is open & & & 0.131 & & & \\
\hline Less than $50 \mathrm{~h}$ & $5(27.8 \%)$ & $13(72.2 \%)$ & & & & \\
\hline $50-120 h$ & $29(8 \%)$ & $340(92 \%)$ & & & & \\
\hline 7 days $24 / 24$ & $8(25.8 \%)$ & $23(74.2 \%)$ & & & & \\
\hline Pharmacist's working hours per week & & & 0.148 & & & \\
\hline Less than $40 \mathrm{~h}$ & $10(10.7 \%)$ & $83(89.3 \%)$ & & & & \\
\hline More than $40 \mathrm{~h}$ & $32(10 \%)$ & 287 (90\%) & & & & \\
\hline
\end{tabular}

$N$ frequency, $\%$ percentage, aOR adjusted odds ratio, $95 \% \mathrm{Cl} 95 \%$ confidence interval

developing immunization training programs to ensure safe and effective administration of vaccines by pharmacists [19]. Such programs show their success in the Maritimes, in which $97 \%$ of pharmacists felt prepared to administer immunizations following completion [2].
In regard to community pharmacists' knowledge, our results showed that the majority of respondents were knowledgeable in different domains except the domain related to vaccine contraindications and precautions. Good knowledge is crucial to expand the scope of 
practice of pharmacists as it supports them in providing adequate education to the public and, consequently, improving their performance and confidence in administrating vaccines. However, this study indicates that respondents lack the necessary knowledge of precautions and contraindications of vaccines, and those related to its administration such as the possibility of administration of inactivated vaccines at the same time or at any time before or after a live vaccine. Also, knowledge regarding the fact that local adverse reaction occurring at the injection site within few hours of administration and that are usually mild and self-limited, was not well recognized. These gaps in knowledge may need to be narrowed and underline a crucial need for strategies to educate community pharmacists about particular aspects of the contraindications and precautions of vaccines through continuing medical education, supplementary professional information, and additional patient educational materials [20]. It should be noted that a good proportion of the participants recognized the need for further education in this field.

It is notable that our results proved positive attitude toward utilization of pharmacists as immunizers. Most of pharmacists appraised the importance of their role in advertising and promoting vaccination among public. This is consistent with the findings of a study conducted in Italy that investigated KAP regarding vaccinations by community pharmacists in Italy [21]. Moreover, pharmacists believed that allowing them to vaccinate can reduce costs paid by patients and that pharmacies are easily accessible to the community which will improve the overall vaccination rate among adults as they feel more comfortable. Our results aligned with the findings of many studies that showed that vaccination costs were less when this service was provided by pharmacists, compared to those that were physician-administered [22]. Another study showed that immunization rates against influenza were higher for individuals aged more than years old in areas where pharmacists provided vaccinations, most likely due to improved accessibility and convenience [23, 24]. Finally, increased vaccination rate will be translated by a decrease in mortality and hospitalizations rates in elderly patients; hence, reduction of the cost related to direct medical care $[25,26]$.

In addition, $84.7 \%$ of pharmacists agreed that they should be legally permitted to administer vaccines. This highlights the importance to focus on statutory reform to enable pharmacists to provide vaccination under the umbrella of law [27].

Since only half of respondents agreed that pharmacists have received adequate teaching/training about vaccine administration during their education, additional training for proper immunization practices is highly recommended. This should be synchronized with regulation changes anticipated by the profession and pharmacy schools to expand the scope of practice and enable pharmacist-administered vaccination.

Regarding the factors necessary for the implementation of vaccination services in community pharmacies, participants indicated that support of health authorities (Ministry of Public Health and Order of Lebanese Pharmacists), statutory allowance, patient demand, pharmacist interest and continuous education and training workshops on immunization, safe administration and handling of vaccines are needed. Consistently, many studies found similar results with respect to essential elements identified, such as legal liability and formal education [28, 29]. With respect to patient demand, CDC estimates that almost $20 \%$ of the 2010-2011 influenza adult vaccinations were administered by pharmacists [30].

In terms of factors associated with CPs' good knowledge, our findings showed that CPs with older age, and working in pharmacies in Bekaa and North have lower knowledge score than their counterparts. However, CPs with high educational level, previous experience in immunization and working in urban areas showed higher tendency to have good knowledge level. Our results were comparable to the findings of a study conducted in Italy that revealed that higher level of knowledge was reported among younger CPs and those with a lower number of years since degree [21]. The role of higher education in predicting better vaccination knowledge might be due that they have more opportunities to learn and receive adequate education and training through their university pharmacy curricula. Given that CPs can be a key point of contact for patients especially who live in rural areas, our findings highlighted the importance of improving the knowledge of the CPs who worked in such areas.

Continuous education and training workshops on immunization, safe administration and handling of vaccines are recommended in addition to the formal certification in vaccine administration as requisite for allowing pharmacists to be immunizers. Vaccine adverse event reporting systems are essential to ensure vaccine safety and surveillance, and maintain people's confidence in vaccines. There is need to establish immunization records which allow pharmacists to identify missed vaccinations, offer reminders to patients, and update immunization records to improve reporting of immunization coverage. Further integration of such systems and procedures across healthcare providers are needed for pharmacists to be incorporated in the overall health system to present a united front in offering vaccination services. Lastly, it is necessary to prepare standards as well as a legal framework for the provision of such services. 


\section{Limitations of the study}

Some limitations of this study should be acknowledged. First, the cross-sectional design of this study does not allow us to infer causality. Second, our study relies on community pharmacists' self-reported information, which makes it prone to the disadvantages of desirability biases. Furthermore, this online questionnaire might have favored a selection bias since it might only allow the participation of community pharmacists who have access to online resources. Lastly, recall bias could have occurred particularly for the questions related to past behavior.

\section{Conclusion}

Most of Lebanese community pharmacists are willing to offer immunizations. Thus, the expansion of CPs scope of practice to include the provision of vaccine required the implementation of a national plan. This plan can encompass the following pillars that should be incorporated in parallel: strengthening knowledge and education about the topic for graduated pharmacist, incorporating vaccines and immunization in the academic curricula, offering post-graduate certificate and diploma for eligibility to administer vaccines with periodic re-certification, enhancing the role of pharmacovigilance and reporting within this scope and, statutory reform. Future studies are needed to examine pharmacists' perceived barriers about immunization, as well as the determinants of their willingness to administer vaccines.

\section{Acknowledgements}

The authors acknowledge Mr. Mohamad Noureddine and Mrs. Fatima Awada for their assistance in data collection. The authors also thank all community pharmacists who participated in this study.

\section{Authors' contributions}

Conception and design: DY, SF, HH and LAA. Analysis and interpretation of the data: DY and LAA. Drafting of the article: DY, SF, HH and LAA. Critical revision of the article for important intellectual content: DY, SF, LAA and $\mathrm{HH}$. Final approval of the article: DY, SF, LAA and $\mathrm{HH}$.

\section{Authors' information}

Dalal Youssef, MSc, MPH, RSM, PhD candidate, ISPED bordeaux, Preventive medicine department, Ministry of public Health, Lebanon. Linda Abou Abbas, $\mathrm{MPH}, \mathrm{PhD}$, Ministry of Public Health, Epidemiological surveillance unit. Hamad Hassan, PharmD, PhD, Ministry of Public Health. Suzan Farhat, BS pharmacy, Masters Candidate.

\section{Funding}

No funding was received.

\section{Availability of data and materials}

Data are available from the corresponding authors upon reasonable request.

\section{Declarations}

\section{Ethics approval and consent to participate}

A written informed consent was obtained from participants. They were informed that all information would be gathered anonymously and handled confidentially and that their participation is voluntary. The questionnaire was collected only in subjects who expressed consent for study participation. This study is exempt from ethical approval in the ministry of Public Health. As individual participants cannot be identified based on the presented material, this study caused no plausible harm or stigma to participants. The study design assured adequate protection of study participants, and neither includes clinical data about patients nor configures itself as a clinical trial.

\section{Consent for publication}

Not applicable.

\section{Competing interests}

The authors declare that they have no competing interests.

\section{Author details}

${ }^{1}$ Preventive Medicine Department, Ministry of Public Health, Beirut, Lebanon. ${ }^{2}$ Research Center for Population Health (BPH), Institut de santé publique d'épidémiologie et de développement (ISPED), Bordeaux University, Bordeaux, France. ${ }^{3}$ Neuroscience Research Center, Faculty of Medical Sciences, Lebanese University, Beirut, Lebanon. ${ }^{4}$ Epidemiological Surveillance Unit, Ministry of Public Health, Beirut, Lebanon. ${ }^{5}$ Lebanese University, Beirut, Lebanon. ${ }^{6}$ Ministry of Public Health, Beirut, Lebanon.

Received: 28 July 2021 Accepted: 8 October 2021

Published online: 24 October 2021

\section{References}

1. Rémy $V$, Zöllner Y, Heckmann U. Vaccination: the cornerstone of an efficient healthcare system. J Mark Access Health Policy, 2015. 3.

2. Edwards $\mathrm{N}$, et al. Pharmacists as immunizers: a survey of community pharmacists' willingness to administer adult immunizations. Int J Clin Pharm. 2015:37(2):292-5.

3. Anderson EL. Recommended solutions to the barriers to immunization in children and adults. Mo Med. 2014;111(4):344-8.

4. Hepler CD, Strand LM. Opportunities and responsibilities in pharmaceutical care. Am J Hosp Pharm. 1990;47(3):533-43.

5. Grabenstein JD. Pharmacists and immunization: increasing involvement over a century. Pharm Hist. 1999;41(4):137-52.

6. Ecarnot $F$, et al. Pharmacy-based interventions to increase vaccine uptake: report of a multidisciplinary stakeholders meeting. BMC Public Health. 2019:19(1):1698.

7. Rosado H, Bates I. An overview of current pharmacy impact on immunisation: a global report. 2016

8. Richardson WM, Wertheimer Al. A review of the pharmacist as vaccinator. Innov Pharm, 2019. 10(3).

9. Schwerzmann J, et al. Evaluating the impact of pharmacies on pandemic influenza vaccine administration. Disaster Med Public Health Prep. 2017;11(5):587-93.

10. Isenor JE, Bowles SK. Opportunities for pharmacists to recommend and administer routine vaccines. Can Pharm J (Ott). 2019;152(6):401-5.

11. Bartsch SM, et al. Epidemiologic and economic impact of pharmacies as vaccination locations during an influenza epidemic. Vaccine. 2018;36(46):7054-63.

12. Bacci $\mathrm{J}$, et al. The effects of vaccination forecasts and value-based payment on adult immunizations by community pharmacists. Vaccine. 2019;37(1):152-9.

13. Yemeke TT, et al. A systematic review of the role of pharmacists in vaccination services in low- and middle-income countries. Res Social Adm Pharm. 2021;17(2):300-6.

14. Kirkdale $C L$, et al. Benefits of pharmacist-led flu vaccination services in community pharmacy. Ann Pharm Fr. 2017;75(1):3-8.

15. Isenor JE, O'Reilly BA, Bowles SK. Evaluation of the impact of immunization policies, including the addition of pharmacists as immunizers, on 
influenza vaccination coverage in Nova Scotia, Canada: 2006 to 2016. BMC Public Health. 2018;18(1):787.

16. Alameddine M, Bou Karroum K, Hijazi MA. Upscaling the pharmacy profession in Lebanon: workforce distribution and key improvement opportunities. Human Resour Health. 2019;17(1):47.

17. Medawar M, Aboul Ela M, Domiati S. Assessment of community pharmacists' involvement in public health promotion services in Beirut, Lebanon. BAU J-Health Wellbeing. 2020;3(1):9.

18. Beaton D, et al. Guidelines for the process of cross-cultural adaption of self-report measures. Spine. 2001;25:3186-91.

19. Canadian Society of Hospital Pharmacists. Immunization Competencies Education Program (ICEP). [Internet]. Ottawa (ON): Canadian Society of Hospital Pharmacists; 2014 [cited 2014 Nov 16]. http://www.cshp.ca/ programs/onlineeducation/icepCourse_e.asp. Accessed 29 June 2021.

20. Bach AT, Goad JA. The role of community pharmacy-based vaccination in the USA: current practice and future directions. Integr Pharm Res Pract. 2015;4:67-77.

21. Della Polla G, et al. Investigating knowledge, attitudes, and practices regarding vaccinations of community pharmacists in Italy. Hum Vaccin Immunother. 2020;16(10):2422-8.

22. Prosser $L A$, et al. Non-traditional settings for influenza vaccination of adults: costs and cost effectiveness. Pharmacoeconomics. 2008;26(2):163-78.

23. Steyer $\mathrm{TE}$, et al. The role of pharmacists in the delivery of influenza vaccinations. Vaccine. 2004;22(8):1001-6.
24. Goad JA, et al. Vaccinations administered during off-clinic hours at a national community pharmacy: implications for increasing patient access and convenience. Ann Fam Med. 2013;1 1(5):429-36.

25. Nichol KL. The efficacy, effectiveness and cost-effectiveness of inactivated influenza virus vaccines. Vaccine. 2003;21(16):1769-75.

26. Dalton K, Byrne S. Role of the pharmacist in reducing healthcare costs: current insights. Integr Pharm Res Pract. 2017;6:37-46.

27. Schmit CD, Penn MS. Expanding state laws and a growing role for pharmacists in vaccination services. J Am Pharm Assoc. 2017;57(6):661-9.

28. Neuhauser MM, et al. Involvement of immunization-certified pharmacists with immunization activities. Ann Pharmacother. 2004;38(2):226-31.

29. Kamal K, Madhavan S, Maine L. Impact of the American Pharmacists Association's (APhA) immunization training certification program. Am J Pharm Educ. 2003;67:124.

30. Lu P-J, et al. Surveillance of influenza vaccination coverage - United States, 2007-08 through 2011-12 influenza seasons. Morb Mortal Wkly Rep Recomm Rep. 2013;62(4):1-28.

\section{Publisher's Note}

Springer Nature remains neutral with regard to jurisdictional claims in published maps and institutional affiliations.
Ready to submit your research? Choose BMC and benefit from:

- fast, convenient online submission

- thorough peer review by experienced researchers in your field

- rapid publication on acceptance

- support for research data, including large and complex data types

- gold Open Access which fosters wider collaboration and increased citations

- maximum visibility for your research: over 100M website views per year

At BMC, research is always in progress.

Learn more biomedcentral.com/submissions 